\title{
FIRST LAPITA SETTLEMENT AND ITS CHRONOLOGY IN VAVA'U, KINGDOM OF TONGA
}

\author{
David V Burley ${ }^{1}$ Sean P Connaughton \\ Department of Archaeology, Simon Fraser University, Burnaby, British Columbia V5A 1S6, Canada.
}

\begin{abstract}
Beginning approximately cal $1400 \mathrm{BC}$, Austronesian-speaking Lapita peoples began a colonizing migration across Oceania from the Bismarck Archipelago to western Polynesia. The first point of entry into Polynesia occurred on the island of Tongatapu in Tonga with subsequent spread northward to Samoa along a natural sailing corridor. Radiocarbon measurements from recent excavations at 4 sites in the northern Vava'u islands of Tonga provide a chronology for the final stage of this diaspora. These dates indicate that the northern expansion was almost immediate, that a paucity of Lapita sites to the north cannot be explained as a result of lag time in the settlement process, and that decorated Lapita ceramics disappeared rapidly after first landfalls.
\end{abstract}

\section{INTRODUCTION}

One of the most exceptional exploration and colonization events in world prehistory took place in western and central Oceania in the approximate interval 1400-900 cal BC. It was undertaken by the "Lapita peoples" (after Kirch 1997), a maritime adapted group of Austronesian language family speakers. The name Lapita derives from a site on the Grand Terre (main island) of New Caledonia where in 1952 a distinctive style of decorated pottery was recovered by E W Gifford and R Shutler Jr. The diaspora began in the Bismarck Archipelago off the northeast coast of New Guinea and extended $4500 \mathrm{~km}$ eastward to the western Polynesian islands of Tonga and Samoa. This event is exceptional for it was completely undertaken by watercraft over vast distances of uncharted waters. It also resulted in the initial human settlement of a large part of the world map, and it set the stage for subsequent settlement expansion throughout Micronesia and Polynesia.

Lapita ceramics provide a highly visible marker for the Lapita diaspora, and research on associated sites has been revealing over the past 4 decades. Many questions remain, nevertheless, especially with respect to routes, regional relationships, and settlement chronology in different parts of the Lapita expanse. In the following paper, we address one of these regional chronologies through presentation of new radiocarbon dates for 4 Lapita sites in the northern Tongan islands of Vava'u, an area at the extreme eastern end of Lapita site distribution (Figure 1). The region is significant for it is intermediary on a natural sailing corridor from southern Tonga, where abundant Lapita sites are recorded, to Samoa where but a single site is known and where the diaspora ended (Kirch 1997). The implications of the Vava'u dates, and the data with which they are associated, shed light on the timing and nature of the final phase of Lapita colonization in Oceania.

\section{FIRST LAPITA SETTLEMENT IN WESTERN POLYNESIA}

Research into the initial settlement of western Polynesia, inclusive of the Fijian islands of Lau, has been substantial and ongoing since the 1960s (see Burley 1998; Anderson and Clark 1999). Prior to 1990 the chronology for this settlement was fraught with problems, leading to claims of 1400 to $1200 \mathrm{cal}$ BC for initial landfalls (Kirch 1988:241). This date had people arriving in Tonga shortly after their departure from the Bismarck Archipelago, supporting Diamond's (1988) characterization of an "express train to Polynesia" migration. Reconsideration and recalibration of existing ${ }^{14} \mathrm{C}$ dates (Spriggs 1996; Spennemann and Head 1997; Dickinson and Green 1998) and an intensive research program on Lapita sites of southern and central Tonga with over 55 new ${ }^{14} \mathrm{C}$ dates (Burley et al.

\footnotetext{
${ }^{1}$ Corresponding author. Email: burley@ $@$ su.ca.
} 


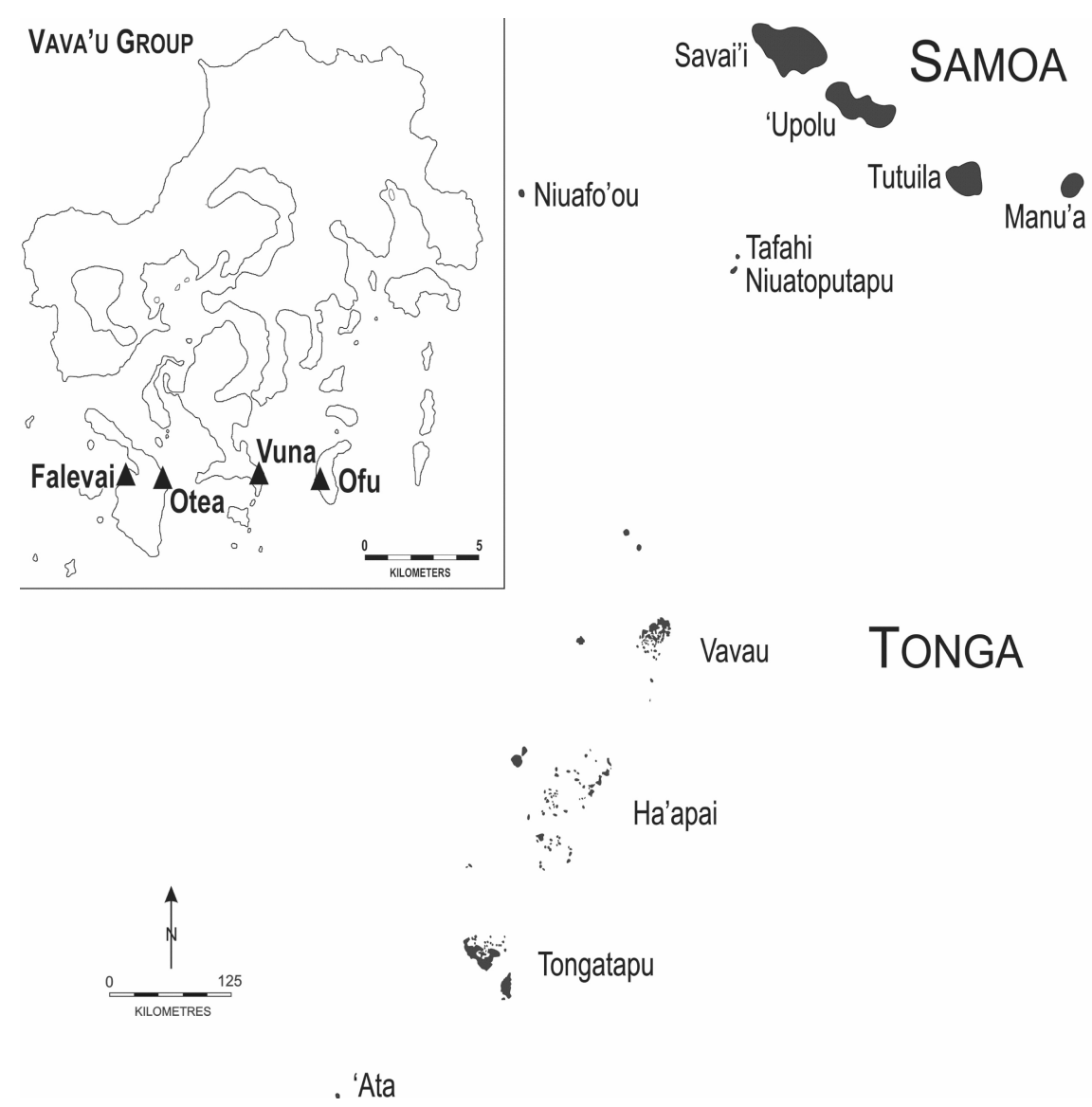

Figure 1 Vava'u site locations as well as Tongan and Samoan archipelagoes with island names mentioned in text.

1999, 2001; Steadman et al. 2002) provide a somewhat clearer picture today. Based on Lapita ceramic types, and in consideration of the existing ${ }^{14} \mathrm{C}$ chronology, first Tongan settlement is identified at the site of Nukuleka on the southern island of Tongatapu at approximately cal 900 BC (Burley and Dickinson 2001). A major expansion of this settlement occurred on Tongatapu during the next half-century with extension into most habitable islands of the central Tongan Ha'apai group (Burley et al. 1999). Voyaging to Ha' apai was facilitated by strong southeast tradewinds. These create a natural sailing corridor north along the Tongan chain from Ha' apai to Vava'u to Niuatoputapu and ultimately the islands of Samoa (Figure 1).

Previous and recent research programs on Tongatapu and the islands of Ha' apai have documented in excess of 25 Lapita site locales with decorated ceramics. As one moves north, however, only single sites were reported for Vava'u (Davidson 1971), Niuatoputapu (Kirch 1988), and Samoa (Dickinson and Green 1998). In the case of Vava'u, the site consisted of no more than a surface find of 2 sherds with Lapita-style decoration. The limited distribution to the north appears anomalous in light of the tradewinds-based sailing corridor as described. To resolve the issue of site distribution and to provide a chronology for northward expansion, new archaeological field studies were undertaken in Vava'u between 2003 and 2005. Five sites with decorated Lapita ceramics were discovered, with 3 having a substantial Lapita occupation. Four sites were given limited excavations resulting in $11{ }^{14} \mathrm{C}$ 
dates associated with either the initial Lapita settlement phase or a sequent Polynesian Plainware phase (Figures 1 and 2). In southern and central Tonga, the latter is estimated to occur within a 2century time span after first settlement, and it is distinguished by the disappearance of decorated ceramics as the name implies (Burley 1998:359). Kirch and Green (2001) correlate this transition with the development of an ancestral Polynesian culture, a template from which all subsequent Polynesian cultures emerged.

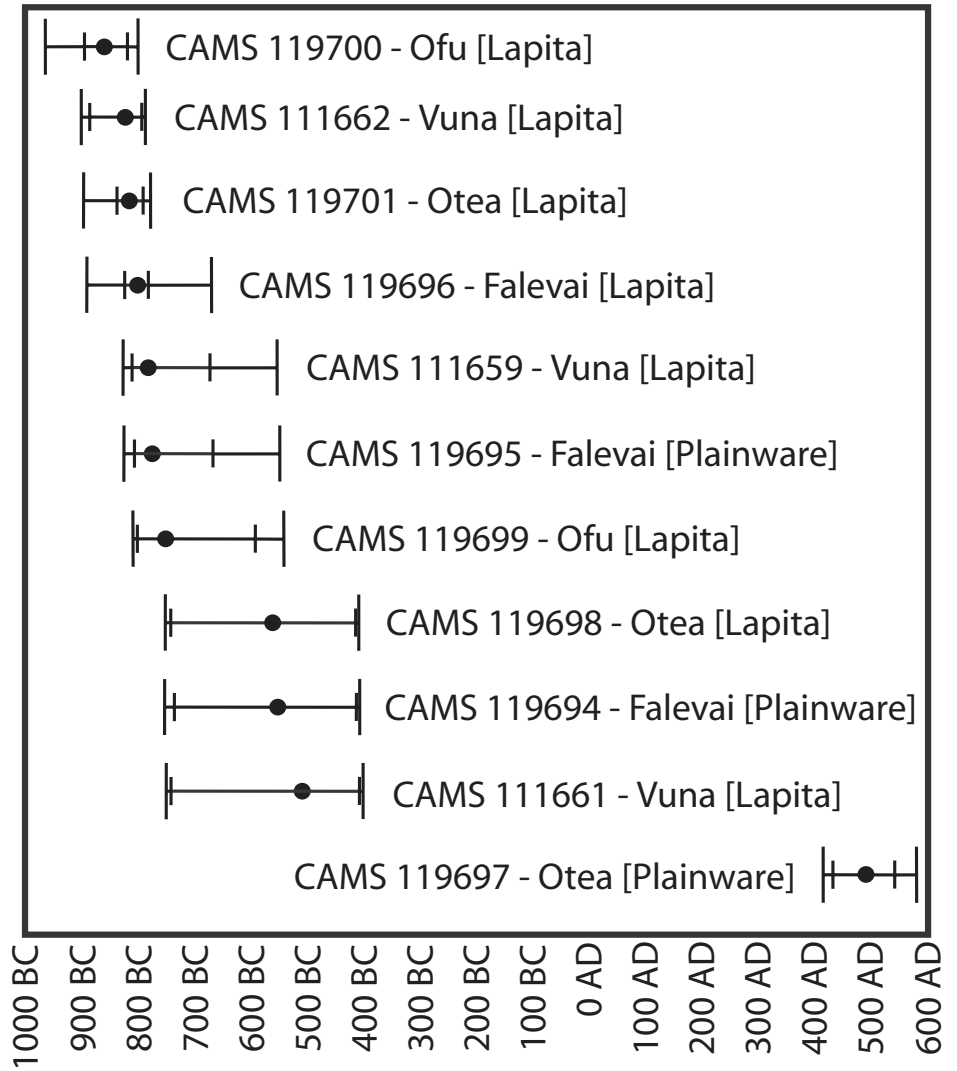

Figure 2 Plot of median probabilities and 1- $\sigma$ and 2- $\sigma$ calibrated ranges for Vava'u dates

\section{RADIOCARBON SAMPLES AND CONTEXTS}

All 4 of the excavated archaeological sites in Vava'u are situated on back beach sand flats or ridges with initial Lapita occupation now occurring at depths below surface of between $0.7 \mathrm{~m}$ and $2.0 \mathrm{~m}$ (Table 1). More recent cultural strata in these sites incorporate intrusive features, which, combined with trampling during site use, potentially create problems for ${ }^{14} \mathrm{C}$ dating. Excavation control and discrete sample selection have been requisite to both the dates reported here and those from previous work in Ha'apai and Tongatapu noted above. Selected samples are exclusively wood charcoal. These typically occurred as small concentrations of flecks or chunks within sealed stratigraphic contexts. None have been identified to species. The dating of occupational strata from charcoal scatters, as opposed to direct dating of features or artifacts, might be questioned (Best 2002:81). Previous results, however, have proven the approach robust (see Burley et al. 1999, 2001). 
Table 1 Vava'u sites with excavated Lapita/Polynesian Plainware phase components.

\begin{tabular}{lllll}
\hline Site & Island & $\begin{array}{l}\text { Excavated } \\
\text { area }\left(\mathrm{m}^{2}\right)\end{array}$ & $\begin{array}{l}\text { Max. depth of } \\
\text { deposit }(\mathrm{m})\end{array}$ & $\begin{array}{l}\text { Nr. of }{ }^{14} \mathrm{C} \\
\text { dates }\end{array}$ \\
\hline Ofu & Ofu & 22 & 0.9 & 2 \\
Vuna & Pangaimotu & 25 & 1.3 & 3 \\
Otea & Kapa & 16 & 2.0 & 3 \\
Falevai & Kapa & 13 & 1.8 & 3 \\
\hline
\end{tabular}

All dates are AMS measurements. Samples were pretreated in the Department of Archaeology at Simon Fraser University employing the acid-base-acid method. A portion of each was combusted and submitted for measurement as a purified $\mathrm{CO}_{2}$ sample to the Center for Accelerator Mass Spectrometry (CAMS), the Lawrence Livermore National Laboratory, Davis, California. A second portion $(1.0 \mathrm{mg})$ was sent to Iso-Analytical Inc. at the University of British Columbia for stable isotope measurement. CAMS dates were corrected for associated $\delta^{13} \mathrm{C}$ values. Calibrations were carried out using the CALIB 5.1 radiocarbon calibration program (Stuiver and Reimer, http://calib.qub.ac.uk/ calib/) applying the Southern Hemisphere calibration curve, SHCal04 (McCormac et al. 2004).

\section{OBSERVATIONS, IMPLICATIONS, AND CONCLUSIONS}

With exceptions to be noted, the $11{ }^{14} \mathrm{C}$ dates when calibrated provide a coherent chronology for the sites from which they derive and for first settlement in the northern islands of Vava'u (Figure 2, Appendix). We offer 5 observations on this chronology with brief discussion of each relative to implications for Lapita settlement in western Polynesia.

1. The earliest ${ }^{14} \mathrm{C}$ dates from each of the Vava'u sites significantly overlap at $2-\sigma$ calibration. Indeed, calibrated dates for initial occupation of the Vuna, Otea, and Falevai sites are all but indistinguishable (Figure 2). The fourth site, Ofu, appears slightly earlier, potentially representing first landfall in Vava'u occurring in the interval 900-850 cal BC. This interpretation is supported by a greater diversity of Lapita ceramic styles and motifs at Ofu, and by the site's faunal assemblage, which has abundant numbers of extinct land birds. That being said, and taking into consideration the remaining ${ }^{14} \mathrm{C}$ dates associated with Lapita phase components, it reasonably can be argued that all sites were occupied contemporaneously between first settlement and cal $800 \mathrm{BC}$.

2. Calibrated 2- $\sigma$ dates for first settlement in Vava'u cannot be reliably differentiated from dates for first settlement on the southern island of Tongatapu (Burley et al. 2001) and in the central Ha'apai group (Burley et al. 1999). The Vava'u dates, therefore, indicate an immediate exploration northward along the Tonga/Samoa travel corridor following initial settlement on Tongatapu. This further implies that a limited distribution of Lapita sites to the north in Samoa cannot be explained by lag time in the settlement process.

3. The site of Falevai is unique within Tonga insofar as it appears to have been founded during the Lapita/Polynesian Plainware transition when decorated Lapita ceramics were in the process of disappearing. Only a very small number of sherds within the ceramic assemblage are decorated, and these are associated with the initial occupation strata only. This context, then, provides bracketing ${ }^{14} \mathrm{C}$ dates of $2685 \pm 35 \mathrm{BP}$ (CAMS 119696) and $2645 \pm 35 \mathrm{BP}$ (CAMS 119695) for the loss of decorated ceramics in Vava'u. This is slightly earlier than the $650 \mathrm{cal}$ BC estimated time line for transition to Polynesian Plainware ceramics elsewhere in Tonga (Kirch 1988:242; Burley 1998:353; Burley et al. 1999:64). At $2 \sigma$, this interval substantially overlaps with Lapita dates from other sites in Vava' $u$, indicating that the disappearance of decorated ceramics may have taken place very shortly after initial settlement. 
4. The end of the Polynesian Plainware phase in Tonga is marked by a complete loss of ceramics from the material culture suite. At the site of Otea in Vava'u, the uppermost stratum incorporating Polynesian Plainware phase ceramics is capped and separated from aceramic strata by a very compact shell layer of Strombus luhuanus. A date of $1615 \pm 35$ BP (CAMS 119697) associated with this layer establishes a terminus post quem for the loss of ceramics at the end of the Plainware phase. This date supports an earlier approximation of cal AD 400 for this transition elsewhere in Tonga (Burley 1998:360).

5. Calibration curve flattening for the interval 2530-2420 BP results in multiple calibration curve intercepts and a substantial widening in the calibrated age for dates falling within the range. Single dates from Falevai, Otea, and Vuna are affected by this problem. The latter two, respectively, $2505 \pm 30$ BP (CAMS 119698) and 2480 \pm 30 BP (CAMS 111661), have been associated with a Lapita occupation context. Even when calibrated at the 2- $\sigma$ range, the upper end of the range does not abut with the lower end of the range for calibrated Lapita dates nor the transitional dates at Falevai (Figure 2). We conclude, therefore, that the charcoal upon which these dates are based is intrusive from a Polynesian Plainware phase component above.

The Vava'u dates presented here provide a reasonable time line for the final phase of Lapita migration and first settlement in northern Tonga beginning approximately 900-850 cal BC. These dates also imply a rapid loss of decorated pottery marking the transition from the Lapita phase to a Polynesian Plainware phase. Parallels to this sequence and coincidental support for these interpretations occur in Samoa where there exists but a single site with decorated Lapita pottery, and where archaeologists have associated the earliest ${ }^{14} \mathrm{C}$ dates with Polynesian Plainware ceramics (Clark 1993; Kirch 1993).

\section{ACKNOWLEDGMENTS}

We acknowledge and thank Erle Nelson and Cheryl Takahashi in the Department of Archaeology, Simon Fraser University, for carrying out pretreatment and combustion of the samples, and for submission to CAMS on our behalf. For field assistance and support in Tonga, we also acknowledge the Tongan Traditions Committee and Palace Office in Nuku'alofa as well as the Governor's Office in Vava'u. Project funding was received from a Social Sciences and Humanities Research Council of Canada grant to Burley and we are grateful for this and earlier funding for his long-term studies in Tonga. Andrew Barton and Karine Tache are to be thanked for their respective preparations of the figures.

\section{REFERENCES}

Anderson A, Clark G. 1999. The age of Lapita settlement in Fiji. Archaeology in Oceania 34(1):31-9.

Best S. 2002. Lapita: A View from the East. Auckland: New Zealand Archaeological Association Monograph 24. $113 \mathrm{p}$.

Burley DV. 1998. Tongan archaeology and the Tongan past, 2850-150 BP. Journal of World Prehistory 12(3): 337-92.

Burley DV, Dickinson WR. 2001. Origin and significance of a founding settlement in Oceania. Proceedings of the National Academy of Sciences 98(20): 11,829-31.

Burley DV, Nelson DE, Shutler Jr R. 1999. A radiocarbon chronology for the Eastern Lapita frontier in Tonga. Archaeology in Oceania 34(2):59-72.
Burley DV, Dickinson WR, Barton A, Shutler Jr R. 2001. Lapita on the periphery: new data on old problems in the Kingdom of Tonga. Archaeology in Oceania 36(2):89-104.

Clark JT. 1993. Radiocarbon dates from American Samoa. Radiocarbon 35(2):323-30.

Davidson JM. 1971. Preliminary report on archaeological survey of the Vava'u Group, Tonga. Royal Society of New Zealand Bulletin 8:29-40.

Diamond JM. 1988. Express train to Polynesia. Nature 336:307-8.

Dickinson WR, Green RC. 1998. Geoarchaeological context of Holocene subsidence at the Ferry Bert Lapita sites, Mulifanua, Upolu, Samoa. Geoarchaeology 13(3):239-63. 
Gifford EW, Shutler Jr R. 1956. Archaeological excavations in New Caledonia. Anthropological Records 18: 1-125. Berkeley: University of California Press.

Kirch PV. 1988. Niuatoputapu: The Prehistory of a Polynesian Chiefdom. Themes Burke Memorial Washington State Museum, Monographs, 5. Seattle: Thomas Burke Memorial Washington State Museum. 295 p.

Kirch PV. 1993. Radiocarbon chronology of the To'aga site. In: Kirch PV, Hunt TL, editors. The To'aga Site, Three Millennia of Polynesian Occupation in the Manu'a Islands, American Samoa. Contributions of the University of California Archaeological Research Facility, No. 51. Berkeley: University of California Press. p 85-92.

Kirch PV. 1997. The Lapita Peoples, Ancestors of the Oceanic World. Cambridge: Blackwell. 380 p.

Kirch PV. 2000. On the Road of the Winds: An Archaeological History of the Pacific Islands before European Contact. Berkeley: University of California Press. $446 \mathrm{p}$.

\section{APPENDIX: VAVA'U RADIOCARBON DATES}

CAMS-119699

$2625 \pm 35$

$\delta^{13} \mathrm{C}-25.9$

Ofu Site, Ofu Island

Charcoal, Unit 3, Level 9, $100 \mathrm{~cm}$ below surface, Stratum IV, associated with Lapita occupation level. Collected June 2005. Sample was recovered from cemented beach sand in association with

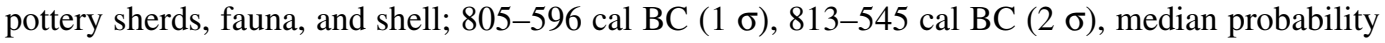
755 cal BC.

CAMS-119700

$2765 \pm 35$

Ofu Site, Ofu Island

$\delta^{13} \mathrm{C}-26.9$

Charcoal, Unit 12, Level 10, $83 \mathrm{~cm}$ below surface, Stratum IV, associated with Lapita occupation level. Collected June 2005. Sample was from a beach sand in association with faunal remains of now extinct birds; $896-820$ cal BC $(1 \sigma), 967-801$ cal BC $(2 \sigma)$, median probability 861 cal BC.

CAMS-119697

$1615 \pm 35$

Otea Site, Kapa Island

$\delta^{13} \mathrm{C}-28.9$

Charcoal, Unit 15, Level 15, $162 \mathrm{~cm}$ below surface, Stratum III. Collected June 2005. Sample was taken from a hearth feature interpreted to be a processing area imbedded within a compact shell midden layer of Strombus luhuanus. The midden layer is intermediate between Polynesian Plainware

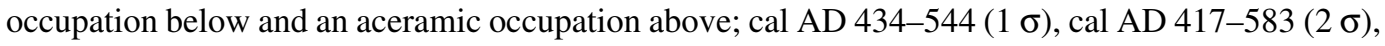
median probability cal AD 493.

CAMS 119698

$2505 \pm 30$

Otea Site, Kapa Island

$\delta^{13} \mathrm{C}-\mathbf{2 4 . 0}$

Charcoal, Unit 16, Level 17, $175 \mathrm{~cm}$ below surface, Stratum III/IV, associated with Lapita occupation level. Collected June 2005; 743-414 cal BC (1 $\sigma)$, 754-409 cal BC (2 $\sigma)$, median probability 562 cal BC. 
CAMS 119701

$2705 \pm 35$

Otea Site, Kapa Island

$\delta^{13} \mathrm{C}-28.9$

Charcoal, Unit 17, Level 17, $180 \mathrm{~cm}$ below surface, Stratum III/IV, associated with Lapita occupation level. Collected June 2005; 838-792 cal BC (1 $\sigma)$, 898-779 cal BC $(2 \sigma)$, median probability 817 cal BC.

CAMS 111659

$2650 \pm 35$

Vuna Site, Pangaimotu Island

$\delta^{13} \mathrm{C}-24.6$

Charcoal, Unit 14, Level 11, $109 \mathrm{~cm}$ below surface, Stratum IIb/III, associated with upper Lapita occupation level. Collected July 2004; 811-673 cal BC $(1 \sigma)$, 833-554 cal BC $(2 \sigma)$, median probability 783 cal BC.

\section{CAMS 111661}

$2480 \pm 30$

Vuna Site, Pangaimotu Island

$\delta^{13} \mathrm{C}-25.5$

Charcoal, Unit 22, Level 11, $106 \mathrm{~cm}$ below surface, Stratum IIb, associated with upper Lapita occupation level. Collected July 2004; 718-408 cal BC (1 $\sigma), 751-401$ cal BC $(2 \sigma)$, median probability $509 \mathrm{cal} \mathrm{BC}$.

CAMS 111662

$2715 \pm 35$

Vuna Site, Pangaimotu Island

$\delta^{13} \mathrm{C}-\mathbf{2 5 . 8}$

Charcoal, Unit 25, Level 12, $125 \mathrm{~cm}$ below surface, Stratum III, associated with lower Lapita occupation level. Collected July 2004; 888-795 cal BC (1 $\sigma)$, 902-788 cal BC $(2 \sigma)$, median probability 824 cal BC.

CAMS 119694

$2500 \pm 35$

Falevai Site, Kapa Island

$\delta^{13} \mathrm{C}-27.9$

Charcoal, Unit 4, Level 11, $105 \mathrm{~cm}$ below surface, Stratum III, associated with the Polynesian Plainware occupation level. Collected July 2005; 737-413 cal BC (1 $\sigma)$, 755-407 cal BC $(2 \sigma)$, median probability 553 cal BC.

CAMS 119695

$2645 \pm 35$

Falevai Site, Kapa Island

$\delta^{13} \mathrm{C}-28.2$

Charcoal, Unit 9, Level 15, $145 \mathrm{~cm}$ below surface, Stratum III, associated with the Polynesian Plain-

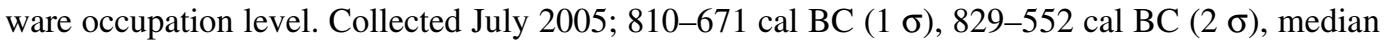
probability $779 \mathrm{cal} \mathrm{BC}$.

CAMS 119696

$2685 \pm 35$

Falevai Site, Kapa Island

$\delta^{13} \mathrm{C}-27.9$

Charcoal, Unit 10, Level 18, $180 \mathrm{~cm}$ below surface, Stratum IV, associated with the Lapita occupation level. Collected July 2005; 828-786 cal BC $(1 \sigma), 895-673$ cal BC $(2 \sigma)$, median probability 805 cal BC. 